\title{
Influence of Female Hormonal Fluctuation on Maximum Occlusal Force
}

\author{
Thaís Marques Simek Vega GONÇALVES \\ Lucíola Maria Rodrigues de VASCONCELOS \\ Wander José da SILVA \\ Altair Antoninha DEL BEL CURY \\ Renata Cunha Matheus RODRIGUES GARCIA
}

Department of Prosthodontics and Periodontology, Piracicaba Dental School, UNICAMP - University of Campinas, Piracicaba, SP, Brazil

\begin{abstract}
Hormonal fluctuations during the menstrual cycle may influence on muscular tensions and probably alter occlusal force. The aim of this study was to evaluate whether hormonal levels affect maximum occlusal force (MOF) of healthy women throughout the different phases of the menstrual cycle. Sixty complete dentate subjects who were not under use of oral contraceptives were selected to participate in this study. MOF was bilaterally evaluated on the molar region, during 3 complete menstrual cycles, using $5.65 \mathrm{~mm}$-wide sensors. Measurements were carried out during each of the following menstrual cycle phases: menstrual, follicular, periovulatory and luteal, presumed by ovulation test. Data were analyzed by one-way ANOVA and Tukey-Kramer test $(\mathrm{p}<0.05)$. Comparisons among menstrual cycle phases showed no differences on MOF $(p=0.27)$. Under the conditions of this study, it may be concluded that hormonal fluctuations during the menstrual cycle do not affect MOF of a sample of healthy women.
\end{abstract}

Key Words: Occlusal force, menstruation, hormonal fluctuation.

\section{INTRODUCTION}

Occlusal force is frequently used to evaluate masticatory function (1) and reflect the maximum voluntary contraction of the masticatory muscles. Maximum occlusal force (MOF) magnitude depends on many variables and is influenced by jaw muscle cross-sectional area $(1,2)$, craniofacial morphology (3), gender $(1,4)$, age $(1)$, occlusion and presence of signs and symptoms of temporomandibular disorders $(4,5)$. In addition, voluntary occlusal force has been found to increase proportionally to the electromyographic (EMG) activity of the jaw closing muscles (6).

The jaw muscles are a group of skeletal muscles responsible for the mastication process. Several studies $(7,8)$ have shown that human skeletal muscle revel estrogen receptors alpha and beta, especially into the nuclei of muscle fibers and the endothelial cells of capillaries (7). According to Baltgalvis et al. (8), the alpha estrogen receptor is responsive to circulating estrogen levels. It suggests that the skeletal tissue is a target for estrogen action, which was confirmed in myotubes by receptors activation when stimulated with estrogen (8). According to Wiik et al. (7), women present a significantly larger number of estrogen receptor beta per square millimeter in skeletal muscle than men after an immunohistochemistry analyzes. The effects of estrogen on skeletal muscle tissue indicate a role in muscle strength development and involvement in carbohydrate and lipid metabolism (9). The evidence indicates that estrogen does not accomplish the muscle function by affecting the muscle size, rather by improving the intrinsic quality of skeletal muscle, whereby fibers are enabled to generate force (10).

A number of studies have examined the influence of estrogen on muscle contractile properties $(7,10-12)$. Some reports $(13,14)$ have noted significant increases in strength and force generation around the time of

Correspondence: Profa. Dra. Renata Cunha Matheus Rodrigues Garcia, Departamento de Prótese e Periodontia, Faculdade de Odontologia de Piracicaba, UNICAMP, Avenida Limeira, 901, 13414-903 Piracicaba, SP, Brasil. Tel: +55-19-2106-5240. Fax: +55-19-2106-5251. e-mail: regarcia@fop.unicamp.br 
ovulation. These results pointed to a fairly rapid effect of estrogen on skeletal muscle force production (14). It has also been suggested that estrogen can influence maximal activity of skeletal muscle fiber (9), increasing maximal contraction force, which could result in muscle fatigue (15), and compromise masticatory function.

The sex hormonal plasma levels predictably fluctuate in the course of the menstrual cycle. The luteal phase extends approximately 14 days after ovulation and is characterized by peaks in estrogen and progesterone (11). Menstruation finishes the luteal phase with abrupt drops in plasma hormones levels. Some women frequently report premenstrual symptoms include headache, dizziness, irritability, nausea and backache which may be directly attributable to increased muscle tension (16), overloading the teeth and possibly altering MOF.

Muscle tension reflects a proportionally increase of the EMG activity of the jaw closing muscles (6). According to Coyne et al. (16), the EMG activity of the facial muscle is influenced by hormonal fluctuations during the menstrual cycle, especially the frontal muscles that shows a reduction in EMG activity in the premenstrual phase, where the hormonal levels are low, compared to follicular phase, where these levels are rising.

As the EMG activity is influenced by hormonal fluctuations (16) and the EMG values represent the force that muscle is able to produce (6), it can be hypothesized that the hormonal fluctuation, that characterizes each menstrual cycle, could be able to affect the MOF. It is of great importance to understand whether, how and to what extent, menstrual cycle can affect stomatognathic functions of healthy women, in order to improve their quality of life. Thus, the aim of this study was to investigate the role of sex hormone fluctuation in the MOF of healthy female subjects.

\section{MATERIAL AND METHODS}

Sixty dentate female subjects with mean age of $23.7 \pm 4.6$ years participated in this study. The participants should present good oral and general health, and regular menstrual cycles. Subjects presenting severe malocclusion, parafunctional habits, facial deformities, temporomandibular disorders, hormonal disease or were under use of oral contraceptives, pregnant or at menopause were excluded. Subjects were selected among patients seeking for dental treatment at Piracicaba
Dental School, University of Campinas, as well as, students and staff of the same Institution. This study was approved by the Ethics Committee of Piracicaba Dental School (Protocol \#072/06) and all subjects who accepted to participate in the study signed an informed consent form.

All subjects presented regular menstrual cycle and were observed during 2 months prior to the study to determine the length of the cycles, which remained between 28 and 32 days. Menstrual cycle was divided considering the date of last menstruation, ovulation period, and on the length of the cycle, into 4 phases (11): (I) Menstrual: first day of bleeding, (II) Follicular; from $6^{\text {th }}$ to $11^{\text {th }}$ day; (III) Periovulatory: from $12^{\text {th }}$ to $16^{\text {th }}$ day, determined by means of the ovulatory predictor test; and (IV) Luteal, stated between the $17^{\text {th }}$ and the $28^{\text {th }}$ day of the menstrual cycle. Menstrual phase was determined by self-report in the first day of bleeding, when subjects were instructed to call the researcher. Based on the length of the cycle, subjects near to the expected time of ovulation were instructed to use Bioeasy ovulation prediction test (BioEasy Diagnóstica, Belo Horizonte, MG, Brazil) until identification of the peak of luteinizing hormone (LH), which occurs immediately before ovulation. In face of a positive result for ovulation, occlusal force was analyzed as soon as possible within a period no longer than $36 \mathrm{~h}$. The MOF were evaluated for 3 complete menstrual cycles, and at each evaluation time. In case of a non-ovulatory cycle, measurements were carried out in the following ovulatory menstrual cycle. All evaluations were performed by a single researcher, in the 4 phases of the menstrual cycle, scheduled for approximately the same time of the day. Thus, all volunteers were evaluated during 3 complete months, totalizing 12 appointments.

\section{Determination of Maximum Occlusal Force}

A bite force transducer (Spider 8; Hottinger Baldwin Messtechnik GmbH, Darmstadt, Germany) composed of two sensors (FSR No151; Interlink Electronics Inc., Camarillo, CA, USA) was used and the signs were registered, amplified and analyzed by the software Catman Easy (Hottinger Baldwin Messtechnik $\mathrm{GmbH}$ ) (17). The sensors (FSR \#151; Interlink Electronics Inc.) were $1.2 \mathrm{~mm}$ in diameter and 0.25 $\mathrm{mm}$ thick, and were protected from deformities during clenching on both sides by 1.0 -mm-thick metal disks of the same diameter, and 1.7-mm-wide rubber disks, 
resulting in a 5.65-mm-wide assembly. The operator positioned the sensors bilaterally on first molar region (Fig. 1) and the subjects were instructed to occlude as hard as they could during $7 \mathrm{~s}$. Measurement was performed twice with a 5-min interval for release and the highest measurement value (in Newton) was used as result of the MOF.

The errors of repeated measurements (Se) for MOF were assessed from 2 separate occasions of 20 randomly selected subjects (n), using intraclass correlation coefficients (ICCs) at a confidence interval of $95 \%$. No differences were found between measurements and the ICC was 0.92 .

\section{Statistical Analysis}

Data were analyzed using ANOVA, considering the MOF as a dependent variable and menstrual cycle phases as independent variables. Data that did not fit the assumptions of normal distribution of errors and equality of variances were transformed. Tukey HSD test was used for post-ANOVA comparisons $\left(\mathrm{y}^{* *} 0.1\right)$. All analyses were performed using the SAS software (version 8.01; SAS Institute Inc., Cary, NC, USA), and a p-value of $<0.05$ was considered as statistically significant. the menstrual cycle.

Although few studies have examined the outcome of the menstrual cycle influence on the strength of the masticatory muscles, the results of this study are consistent with Gonçalves et al. (18), which reported no changes in MOF or masticatory performance over the different phases of the menstrual cycle. The authors concluded that female sex steroids affect different body systems; however, there is no conclusive evidence of their effects on the masticatory system.

Studies performed with other body muscles (11), seem to agree and support the present findings. According to Janse de Jonge et al. (11), no significant changes were found in muscle strength of quadriceps

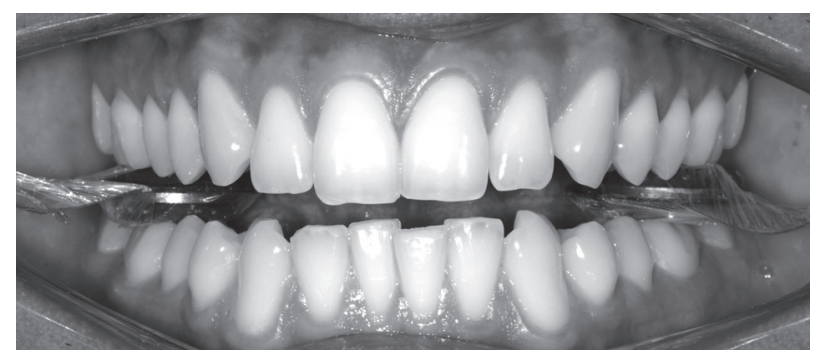

Figure 1. Sensors bilaterally positioned on the first molar region.

\section{RESULTS}

The MOF values obtained in each phase of the 3 consecutive menstrual cycles are presented in Table 1. There was no significant difference in MOF values among menstrual cycle phases for normally cycling women $(\mathrm{p}=0.27)$ (Table 2$)$.

\section{DISCUSSION}

Some authors have reported the relationship between facial muscle EMG activity and hormonal fluctuations through the menstrual cycle (16), which could possibly influence the MOF. However, when data were analyzed including all 3 menstrual cycles, it could be seen that contrary to our hypotheses, no significant differences were demonstrated among the phases of the menstrual cycle for MOF $(p=0.27)$. The results of this study suggest that maximum voluntary force of the masticatory muscles is not influenced by the variations in reproductive hormones levels during
Table 2. Mean and standard deviation values for maximum occlusal force (MOF, in $\mathrm{N}$ ) according to menstrual cycle phases.

\begin{tabular}{lc}
\hline Menstrual cycle phase & MOF \\
\hline Menstrual & $454.85 \pm 134.06 \mathrm{a}$ \\
Follicular & $470.44 \pm 152.69 \mathrm{a}$ \\
Ovulatory & $492.12 \pm 136.81 \mathrm{a}$ \\
Luteal & $444.26 \pm 142.59 \mathrm{a}$ \\
\hline
\end{tabular}

Means followed by the same lowercase letter are not statistically different $(\mathrm{p}=0.27)$. 
muscles of women throughout the phases of the menstrual cycle. Importantly, in that study, the use of electrical stimulation ensured maximum quadriceps muscle contraction. In a review article, Constantini et al. (19) also showed that muscular strength does not appear to fluctuate significantly during an ovulatory menstrual cycle. Thus, considering that MOF is related to muscle strength, the findings of the present study seem to be in agreement with those of the above-mentioned authors.

On the other hand, the literature shows some contradictory results. Philips et al. (13) observed a clear rise in maximum voluntary force of adductor pollicis muscle within peak of estrogen, concluding that this hormone has a direct or indirect strengthening action on skeletal muscle. In addition, Sarwar et al. (14) found a significant increase of about $11 \%$ in quadriceps and handgrip strength at ovulatory phase compared with both the follicular and luteal phases.

These conflicting findings could probably be explained by methodological shortcomings, especially related to the menstrual cycle phase's definition. Early studies $(13,14,16)$ investigating the menstrual cycle have often relied on counting the days from the onset of menses. One problem with this method is that, in general, the follicular phase is more variable in length than the luteal phase. Moreover, this method assumes that all women who menstruate regularly also ovulate regularly. However, there is a high incidence of anovulation in women with regular bleeding (20). More recent studies measured the estrogen and progestin concentrations in serum (11) or use an ovulation predictor test (18) in order to avoid anovulatory cycles and to certify, with a confidence level of $95 \%$, the ovulatory phase as indicated by the peak urinary luteinizing hormone serum level (21).

According to the terms in which this study was performed, it is possible to conclude that hormonal fluctuations during menstrual cycle do not affect MOF of healthy women. Well delineated studies with reliable methods for identification of menstrual phases should be performed to better understand how and to what extent female hormonal fluctuation affects stomatognathic functions.

\section{RESUMO}

As flutuações hormonais durante o ciclo menstrual podem influenciar as tensões musculares e possivelmente alterar a força oclusal. O objetivo deste estudo foi avaliar se os níveis hormonais afetam a força máxima oclusal (FMO) de mulheres saudáveis durante as diferentes fases do ciclo menstrual. Sessenta pacientes completamente dentadas que não usavam contraceptivos orais foram selecionadas para participar neste estudo. FMO foi avaliada bilateralmente na região dos molares, durante 3 ciclos menstruais completos, utilizando sensores de 5,65 $\mathrm{mm}$ de espessura. As mensurações foram realizadas durante cada fase do ciclo menstrual: menstrual, folicular e lútea periovulatória, identificadas por teste ovulatório. Os dados foram analisados por ANOVA um critério seguido do teste de Tukey-Kramer $(p<0,05)$. As comparações entre as fases do ciclo menstrual não apresentaram diferenças na FMO $(\mathrm{p}=0,27)$. Segundo as condições deste estudo, pode-se concluir que as flutuações hormonais durante o ciclo menstrual não afetaram a FMO de mulheres saudáveis.

\section{ACKNOWLEDGEMENTS}

We extend sincere thanks to subjects who participated. This study was supported by CAPES.

\section{REFERENCES}

1. Hatch JP, Shinkai RSA, Sakai S, Rugh JD, Paunovich ED. Determinants of masticatory performance in dentate adults. Arch Oral Biol 2001;46:641-648.

2. Raadsheer MC, van Eijden TMGJ, van Ginkel FC, Prahl-Andersen B. Contribution of jaw muscle size and craniofacial morphology to human bite force magnitude. J Dent Res 1999;78:31-42.

3. Gomes SGF, Custodio W, Faot F, Del Bel Cury AA, Rodrigues Garcia RCM. Masticatory features, EMG activity and muscle effort of subjects with different facial patterns. J Oral Rehabil 2010;37:813-819.

4. Hotta PTH, Hotta TH, Bataglion C, Pavão RF, Siéssere S, Regalo $\mathrm{SCH}$. Bite force in temporomandibular dysfunction (TMD) and healthy complete denture wearers. Braz Dent J 2008;19:354-357.

5. Pereira LJ, Steenks MH, de Wijer A, Speksnijder CM, van der Bilt A. Masticatory function in subacute TMD patients before and after treatment. J Oral Rehabil 2009;36:391-402.

6. Tortopidis D, Lyons MF, Baxendale RH. Acoustic myography, electromyography and bite force in the masseter muscle. J Oral Rehabil 1998;25:940-945.

7. Wiik A, Ekman M, Morgan G, Johansson O, Jansson E, Esbjörnsson M. Expression of both oestrogen receptor alpha and beta in human skeletal muscle tissue. Histochem Cell Biol 2009;131:181-189.

8. Baltgalvis KA, Greising SM, Warren GL, Lowe DA. Estrogen regulates estrogen receptors and antioxidant gene expression in mouse skeletal muscle. PLoS One 2010;13:e10164.

9. Campbell SE, Febbraio MA. Effect of ovarian hormones on mitochondrial enzyme activity in the fat oxidation pathway of skeletal muscle. Am J Physiol Endocrinol Metab 2001;281:803808.

10. Lowe DA, Baltgalvis KA, Greising SM. Mechanism behind estrogen's beneficial effect on muscle strength in females. Exerc Sport Sci Rev 2010;38:61-67.

11. Janse de Jonge XAK, Boot CRL, Thom JM, Ruell PA, Thompson MW. The influence of menstrual cycle phase on skeletal muscle contractile characteristics in humans. J Physiol 2001;530:161-166.

12. Enns DL, Tiidus PM. The influence of estrogen on skeletal muscle: sex matters. Sports Med 2010;40:41-58.

13. Phillips SK, Sanderson AG, Birch K, Bruce SA, Woledge RC. Changes in maximal voluntary force of human adductor pollicis muscle during the menstrual cycle. J Physiol 1996;496:551-557. 
14. Sarwar R, Niclos BB, Rutherford OM. Changes in muscle strength, relaxation rate and fatiguability during the human menstrual cycle. J Physiol 1996;493:267-272.

15. Suzuky S, Yamamuru T. Long-term effects of estrogen on rat skeletal muscle. Exp Neurol 1985;87:291-299.

16. Coyne C. Muscle tension and its relation to symptoms in the premenstruum. Res Nurs Health 1983;6:199-205.

17. Fernandes CP, Glantz PO, Svensson SA, Bergmark A. A novel sensor for bite force determinations. Dent Mater 2003;19:118-126.

18. Gonçalves TMSV, Sanchéz-Ayala A, Ambrosano GB, Rodrigues Garcia RCM. Female hormonal fluctuation and masticatory function in patients with anterior disc displacement. Int J Prosthodont 2011;24:320-327.
19. Constantini NW, Dubnov G, Lebrun CM. The menstrual cycle and sport performance. Clin Sports Med 2005;24:e51-e82.

20. De Souza MJ, Miller BE, Loucks AB, Luciano AA, Pescatello LS, Campbell CG, et al.. High frequency of luteal phase deficiency and anovulation in recreasional women runners: blunted elevation in follicle-stimulating hormone observed during luteal-follicular transition. J Clin Endocrinol Metab 1998;83:4220-4232.

21. Miller PB, Soules MR. The usefulness of a urinary LH kit for ovulation prediction during menstrual cycles of normal women. Obstet Gynecol 1996;87:13-17.

Received March 29, 2011

Accepted June 10, 2011 